\title{
Effects of physiological age on residual feed intake of growing heifers
}

\author{
Andrea N. Loyd, Charles R. Long, Andrew W. Lewis, Ronald D. Randel ${ }^{*}$
}

Texas AgriLife Research, Overton, TX, USA; ${ }^{\text {Corresponding Author: r-randel@,tamu.edu }}$

Received 22 July 2011; revised 6 September 2011; accepted 20 September 2011.

\begin{abstract}
Using a retrospective evaluation of feed efficiency, this study investigated the effects of physiological age on residual feed intake (RFI) in growing heifers. Data were collected during 1973 and 1974 at the McGregor location of the Texas Agricultural Experiment Station. Heifers $(n=77)$ were obtained from a large crossbreeding program utilizing a five-breed diallel mating scheme using Angus, Brahman, Hereford, Holstein and Jersey breeds. At approximately 6 months of age, pre-pubertal heifers were individually penned and received ad libitum access to a balanced diet. Individual feed intake and body weight data were collected at 28-day intervals for $\mathbf{8 4}$ days prior to puberty and for $\mathbf{9 0}$ days after puberty. The diet was changed at puberty to provide a lower energy density. Considering all females as cohorts, RFI was calculated for each heifer for each period using separate models for the pre- and post-pubertal periods. A moderate, positive Pearson correlation ( $r=0.48 ; P<0.001)$ was detected between pre- and post-pubertal RFI. Furthermore, heifer RFI rank was compared between the pre- and post-pubertal periods using Spearman rank order correlation and a similar correlation $(r=0.46$; $P<0.001$ ) was revealed. This suggests that RFI determined during the pre-pubertal period may only be a moderate predictor of post-pubertal RFI. As a result, physiological age should be considered when evaluating cattle for feed efficiency using RFI.
\end{abstract}

Keywords: Cattle; Puberty; Residual Feed Intake

\section{INTRODUCTION}

Feed provided to cattle represents a significant portion of the cost of producing beef [1]. Identifying and selecting cattle that are more efficient at utilizing feed re- sources can potentially reduce feed usage. Selection strategies for improving feed efficiency have been shifting away from the conventionally used feed:gain ratio (FG) and are incorporating residual feed intake (RFI) as an indicator of feed efficiency in beef cattle. Many variables can influence the outcome of an RFI evaluation; however, many of these factors can be controlled (i.e. test duration, type and amount of diet provided, selection of cohorts of animals, etc.). The Beef Improvement Federation (BIF) has developed guidelines to standardize the methodology for RFI evaluation [2]. Specific to cohort selection, it is recommended that cattle be at least 240 days of age and not differ by more than 60 days of age at the beginning of an RFI feeding trial [2]. Although cattle may be of similar chronological age, they may differ in physiological maturity since an important biological phenomenon (puberty) may occur during this time in bulls and heifers.

Brody (1945) suggested that puberty coincides with the inflection point of the growth curve, which corresponds to a shift in body composition away from lean accrual and towards fat deposition. Recent studies suggest that differences in body composition may contribute to differences in RFI [4-7]. Since gonadal steroids associated with puberty alter body composition, pre-pubertal RFI may differ from post-pubertal RFI. The objective of this study was to investigate the potential consequences of cohort selection, specifically physiological age, on the outcomes of RFI evaluations. To accomplish our objecttive, RFI was evaluated on heifers during two distinct stages of development (pre- and post-puberty).

Since the expense associated with RFI research is substantial, this study was conducted using feed intake (FI) and body weight (BW) data previously collected from heifers pre- and post-puberty. The FI and BW data were initially reported as a component of an experiment $[8,9]$ that did not include RFI analysis. The current study made use of these historical data to bring new information to RFI research.

Furthermore, there are currently very few research initiatives investigating feed efficiency of replacement 
heifers. Most studies use steers and terminal heifers when evaluating various facets of RFI and feed efficiency [10-13]. Therefore, this study provides unique and relevant RFI data pertaining specifically to heifers that will be retained in the cowherd.

\section{MATERIALS AND METHODS}

\subsection{Animals and Experimental Design}

Data used for this study were collected during 1973 and 1974 from the McGregor location of the Texas Agricultural Experiment Station as previously described $[8,9]$. Heifers $(n=77)$ were obtained from a large crossbreeding program that utilized a five-breed diallel mating scheme. Heifer breeds included straightbred Angus $(\mathrm{n}=7)$, Brahman $(\mathrm{n}=5)$, Hereford $(\mathrm{n}=5)$, Holstein $(\mathrm{n}=$ $6)$ and Jersey $(n=5)$ and $F_{1}$ Angus $\times$ Brahman $(n=3)$, Angus $\times$ Hereford $(n=4)$, Angus $\times$ Holstein $(n=4)$, Angus $\times$ Jersey $(n=5)$, Brahman $\times$ Hereford $(n=6)$, Brahman $\times$ Holstein $(n=6)$, Brahman $\times$ Jersey $(n=6)$, Hereford $\times$ Holstein $(n=5)$, Hereford $\times$ Jersey $(n=5)$ and Holstein $\times$ Jersey $(n=5)$ crosses (reciprocals pooled). Pre-pubertal heifers were individually penned at approximately 6 months of age in $3 \mathrm{~m}$ by $10 \mathrm{~m}$ open, dirt-floored pens and were allowed ad libitum access to a balanced diet. After reaching puberty, the diet was changed for each heifer to reduce energy density (Table 1). Feed intake and BW data were recorded at 28-day intervals for $84 \pm 6$ days prior to puberty and for $90 \pm 4$ days after puberty for each heifer following procedures described by Long et al. (1979). Puberty was defined as the first ovulatory estrus. Heifers were exposed to marker bulls during overnight exercise periods to aid in estrus detection. Heifers were also examined by rectal palpation every 3 weeks and when marked by a bull to determine ovarian activity [9].

\subsection{RFI Calculation}

In order to compare RFI during two distinct physiological periods, the pre-pubertal and post-pubertal periods were considered separately for RFI calculation. As

Table 1. Pre- and post-pubertal diet compositions.

\begin{tabular}{lll}
\hline Ingredient (as fed) & Pre-pubertal & Post-pubertal \\
\hline Sorghum, \% & 48.5 & 33.0 \\
Cottonseed meal, \% & 20.0 & 10.0 \\
Cottonseed hulls, \% & 25.0 & 50.0 \\
Vegetable fat, \% & 4.0 & 4.0 \\
Vitamin/mineral supplement, \% & 2.5 & 3.0 \\
\hline
\end{tabular}

such, a separate model was fitted for each period to determine pre- and post-pubertal RFI. All heifers were considered as cohorts for each of the pre- and post-pubertal RFI calculations. Initial BW and average daily gain (ADG) of each period were computed from linear regression of $\mathrm{BW}$ on day of test using the PROC REG function of SAS (2002). Mid-test BW was estimated for each period using the intercept and slope from the regression and adjusting for 3\% shrink. Metabolic mid-test BW (MMBW) was calculated as mid-test $\mathrm{BW}^{0.75}$ for each period. Expected daily FI was predicted for each period by linear regression of average daily feed intake (ADFI) on MMBW and ADG using the GLM procedure of SAS (2002). The model fitted for each period was

$$
Y_{i}=\beta_{0}+\beta_{1} M M B W_{i}+\beta_{2} A D G_{i},
$$

where $Y_{i}=$ expected daily feed intake, $\beta_{0}=$ the regression intercept, $\beta_{1}=$ the partial regression coefficient of FI on MMBW, and $\beta_{2}=$ the partial regression coefficient of FI on ADG. Residual feed intake was computed for each heifer for each period by subtracting actual feed intake from expected feed intake.

\subsection{Statistical Analysis}

Pearson correlation coefficients were determined using the PROC CORR function of SAS (2002) to correlate pre- and post-pubertal RFI. Spearman rank order correlation was used to evaluate changes in heifer RFI rank from the pre- to post-pubertal periods [15].

\section{RESULTS AND DISCUSSION}

Age, BW, ADG, ADFI, and RFI summary statistics are presented in Table 2. As expected age, BW and ADFI were greater for the post-pubertal period than for the pre-pubertal period. Average daily gain was reduced in the post-pubertal period, likely as a result of the decreased energy density of the diet. By definition, mean RFI was $0.00 \mathrm{~kg} /$ day for both the pre- and post-pubertal periods. The range between the most efficient and least efficient heifers was $2.79 \mathrm{~kg}$ /day for the pre-pubertal period and $6.04 \mathrm{~kg} /$ day for the post-pubertal period. Despite these heifers being individually fed, this range is consistent with previous reports of RFI for growing cattle receiving ad libitum access to feed in groups using GrowSafe ${ }^{\circledR}$ [12] or Insentec [13,16] electronic feeding equipment. Current BIF guidelines suggest that feed intake data obtained from individually-penned cattle are inadequate [2]. However, the initial concept of RFI was published using data from cattle fed in individual pens [17]. Furthermore, recent results suggest that feeding cattle in individual pens yields similar results to groupfeeding cattle as long as the cattle are stimulated to come to the bunk more than once daily [18]. In our study, 
Table 2. Pre- and post-pubertal summary statistics for growing heifers $(\mathrm{n}=77)$.

\begin{tabular}{|c|c|c|c|c|c|c|c|c|}
\hline \multirow[b]{2}{*}{ Trait $^{1}$} & \multicolumn{4}{|c|}{ Pre-pubertal } & \multicolumn{4}{|c|}{ Post-pubertal } \\
\hline & Mean & $\mathrm{SD}^{2}$ & $\operatorname{Min}^{3}$ & $\operatorname{Max}^{4}$ & Mean & $\mathrm{SD}^{2}$ & $\operatorname{Min}^{3}$ & $\operatorname{Max}^{4}$ \\
\hline Initial age, months & 5.6 & 0.6 & 3.9 & 7.6 & 11.8 & 2.0 & 8.6 & 15.9 \\
\hline Age at puberty, months & & & & & 10.9 & 2.0 & 7.7 & 15.4 \\
\hline Test duration, days & 84 & 6 & 78 & 119 & 90 & 4 & 84 & 94 \\
\hline Initial BW, kg & 116.1 & 25.7 & 51.3 & 191.1 & 273.2 & 54.6 & 175.9 & 377.0 \\
\hline Final BW, kg & 196.0 & 33.7 & 108.6 & 285.2 & 333.1 & 60.9 & 223.3 & 454.2 \\
\hline MMBW, kg & 43.0 & 6.1 & 26.1 & 59.3 & 70.8 & 10.1 & 52.3 & 88.8 \\
\hline ADG, kg/day & 0.95 & 0.17 & 0.41 & 1.45 & 0.67 & 0.17 & 0.21 & 1.17 \\
\hline ADFI, kg/day & 6.0 & 1.0 & 3.9 & 8.5 & 9.0 & 1.6 & 5.9 & 13.5 \\
\hline RFI, kg/day & 0.00 & 0.57 & -1.47 & 1.32 & 0.00 & 1.11 & -2.08 & 3.96 \\
\hline
\end{tabular}

${ }^{1} \mathrm{BW}=$ body weight; MMBW = metabolic mid-test body weight; $\mathrm{ADG}=$ average daily gain; ADFI = average daily feed intake; RFI = residual feed intake; ${ }^{2} \mathrm{SD}$ $=$ standard deviation; ${ }^{3} \mathrm{Min}=$ minimum $;{ }^{4} \mathrm{Max}=$ maximum.

feed was transferred to the troughs several times daily such that the cattle were frequently stimulated to consume feed [8].

A Pearson correlation coefficient of $0.48(\mathrm{P}<0.001)$ was detected between pre-pubertal and post-pubertal RFI. Spearman rank order correlation revealed a similar correlation $(\mathrm{r}=0.46 ; \mathrm{P}<0.001)$ between pre-pubertal and post-pubertal RFI. These moderate correlation coefficients suggest that RFI determined prior to puberty may be only a moderate predictor of post-pubertal RFI. These results are consistent with other studies that evaluated RFI on the same cattle at different ages. Archer et al. (2002) reported a moderate phenotypic correlation of 0.40 between RFI measured in heifers during the postweaning period and again as non-gestating, non-lactating cows after two parities. Arthur et al. (2001) compared RFI of weanling and yearling bulls and observed a phenotypic correlation of 0.43 . A genetic correlation of 0.55 was reported between steers evaluated for RFI during the growing and finishing phases [11]. A repeatability estimate for RFI of 0.62 was reported between the growing and finishing phases of Limousin x Friesian heifers [13].

One of the proposed benefits of using RFI as a measure of feed efficiency in beef cattle is that it accounts for between-animal variation in maintenance and growth [20]. Furthermore, RFI is phenotypically independent of its component traits (ADG and MMBW) and should allow for comparisons between animals at different stages of production during the RFI evaluation [21]. Under this principle, the evaluation of RFI using animals of different ages should be valid. However, physiological maturity has been implicated as a source of variation when determining RFI [16] as feed efficiency measurements are dependent on the stage of maturity of the ani- mals at evaluation [22].

As cattle grow, composition of their gain shifts from protein accretion to fat deposition [23]. Since the energetic expense associated with protein accrual is less than for fat deposition [24], the efficiency with which cattle convert feed into BW gain is reduced as they mature. A substantial shift from protein accretion towards adipose deposition occurs around the time of puberty [3]. These changes in body composition associated with advancing physiological maturity could partially explain the moderate correlations between pre- and post-pubertal RFI reported in this study. This suggests that RFI determined during the pre-pubertal period may be only a moderate predictor of feed efficiency during the post-pubertal period.

Admittedly, it is not possible to separate the effects of puberty status from the effects of the diet change from the pre-pubertal to the post-pubertal feeding periods in the current study. To definitively attribute differences in pre-pubertal and post-pubertal RFI, the same diet would have to have been fed throughout the experiment. As this is a retrospective analysis of previously collected data, this could not be controlled. Nonetheless, previous experiments that have evaluated RFI on cattle fed the same diet at different ages observed similar correlations as reported here $[10,19]$. As a result, physiological maturity should be considered when selecting cohorts of cattle for RFI evaluation.

\section{REFERENCES}

[1] Montaño-Bermudez, M., Nielsen, M.K. and Deutscher, G.H. (1990) Energy requirements for maintenance of crossbred beef cattle with different genetic potential for milk. Journal of Animal Science, 68, 2279-2288. 
[2] BIF (2010) Guidelines for uniform beef improvement programs. 9th Edition, Beef Improvement Federation, North Carolina State University, Raleigh, 24-27.

[3] Brody, S. (1945). Bioenergetics and growth, with special reference to the efficiency complex in domestic animals. Reinhold Publishing Corporation, New York.

[4] Richardson, E.C., Herd, R.M., Oddy, V.H., Thompson, J.M., Archer, J.A. and Arthur, P.F. (2001) Body composition and implications for heat production of Angus steer progeny of parents selected for and against residual feed intake. Australian Journal of Experimental Agriculture, 41, 1065-1072. doi:10.1071/EA00095

[5] Basarab, J.A., Price, M.A., Aalhus, J.L., Okine, E.K., Snelling, W.M. and Lyle, K.L. (2003) Residual feed intake and body composition in young growing cattle. $\mathrm{Ca}$ nadian Journal of Animal Science, 83, 189-204. doi:10.4141/A02-065

[6] Lancaster, P.A., Carstens, G.E., Crews Jr., D.H., Welsh Jr., T.H., Forbes, T.D.A., Forrest, D.W., Tedeschi, L.O., Randel, R.D. and Rouquette, F.M. (2009) Phenotypic and genetic relationships of residual feed intake with performance and ultrasound carcass traits in Brangus heifers. Journal of Animal Science, 87, 3887-3896. doi:10.2527/jas.2009-2041

[7] Kelly, A.K., McGee, M., Crews Jr., D.H., Fahey, A.G., Wylie, A.R. and Kenny, D.A. (2010) Effect of divergence in residual feed intake on feeding behavior, blood metabolic variables, and body composition traits in growing beef heifers. Journal of Animal Science, 88, 109-123. doi: $10.2527 /$ jas.2009-2196

[8] Long, C.R., Stewart, T.S., Cartwright, T.C. and Baker, J.F. (1979) Characterization of cattle of a five breed diallel: II. Measures of size, condition and growth in heifers. Journal of Animal Science, 49, 432-447.

[9] Stewart, T.S., Long, C.R. and Cartwright, T.C. (1980) Characterization of cattle of a five-breed diallel. III. Puberty in bulls and heifers. Journal of Animal Science, 50, 808-820.

[10] Arthur, P.F., Renand, G. and Krauss, D. (2001) Genetic parameters for growth and feed efficiency in weaner versus yearling Charolais bulls. Australian Journal of Agricultural Research, 52, 471-476. doi:10.1071/AR00070

[11] Crews Jr., D.H., Shannon, N.H., Genswein, B.M.A., Crews, R.E., Johnson, C.M. and Kendrick, B.A.. (2003) Genetic parameters for net feed efficiency of beef cattle measured during postweaning growing versus finishing periods. Proceedings of the Western Section of the American Society of Animal Science, 54, 125-128.

[12] Lancaster, P.A., Carstens, G.E., Ribeiro, F.R.B., Tedeschi, L.O. and Crews Jr., D.H. (2009) Characterization of feed efficiency traits and relationships with feeding behavior and ultrasound carcass traits in growing bulls. Journal of Animal Science, 87, 1528-1539.

\section{doi:10.2527/jas.2008-1352}

[13] Kelly, A.K., McGee, M., Crews Jr., D.H., Sweeney, T., Boland, T.M. and Kenny, D.A. (2010) Repeatability of feed efficiency, carcass ultrasound, feeding behavior, and blood metabolic variables in finishing heifers divergently selected for residual feed intake. Journal of Animal Science, 88, 3214-3225. doi:10.2527/jas.2009-2700

[14] SAS. (2002) SAS 8.2 user's guide: Statistics. SAS Institute, Inc, Cary, NC.

[15] SPSS. (2005) SPSS 15 user's guide: Statistics. SPSS Incorporated, Chicago, IL.

[16] Mader, C.J., Montanholi, Y.R., Wang, Y.J., Miller, S.P., Mandell, I.B., McBride, B.W. and Swanson, K.C. (2009) Relationships among measures of growth performance and efficiency with carcass traits, visceral organ mass, and pancreatic digestive enzymes in feedlot cattle. Journal of Animal Science, 87, 1548-1557. doi:10.2527/jas.2008-0914

[17] Koch, R.M., Swiger, L.A., Chambers, D. and Gregory, K.E. (1963) Efficiency of feed use in beef cattle. Journal of Animal Science, 22, 486-494.

[18] Cruz, G.D., Rodríguez-Sánchez, J.A., Oltjen, J.W. and Sainz, R.D. (2010) Performance, residual feed intake, digestibility, carcass traits, and profitability of AngusHereford steers housed in individual or group pens. Journal of Animal Science, 88, 324-329. doi: $10.1080 / 028418501127346846$

[19] Archer, J.A., Reverter, A. Herd, R.M., Johnston, D.J. and Arthur P.F. (2002) Genetic variation in feed intake and efficiency of mature beef cows and relationships with postweaning measurements. Proceedings of the 7th World Congress on Genetics Applied to Livestock Production, Montpellier, France, 31.

[20] Arthur, P.F., Renand, G. and Krauss, D. (2001) Genetic and phenotypic relationships among different measures of growth and feed efficiency in young Charolais bulls. Livestock Production Science, 68, 131-139. doi:10.1016/S0301-6226(00)00243-8

[21] Herd, R.M. and Arthur, P.F. (2009) Physiological basis for residual feed intake. Journal of Animal Science, 87 (E-Suppl.), E64-E71.

[22] Arthur, P.F. and Herd, R.M. (2005) Efficiency of feed utilization by livestock-Implications and benefits of genetic improvement. Canadian Journal of Animal Science, 85, 281-290. doi:10.4141/A04-062

[23] Trenkle, A. and Willham, R.L. (1977) Beef production efficiency: The efficiency of beef production can be improved by applying knowledge of nutrition and breeding. Science, 198, 1009-1015. doi:10.1126/science.198.4321.1009

[24] Ferrell, C.L. and Jenkins, T.G. (1985) Cow type and the nutritional environment: Nutritional aspects. Journal of Animal Science, 61, 725-741. 